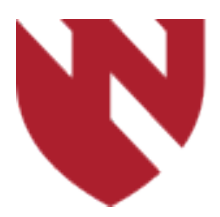

December 2019

\title{
An Overview of Neurology Residency Training in Epilepsy at the University Of Nebraska Medical Center
}

\author{
Daniel Crespo Artunduaga \\ University of Nebraska Medical Center \\ Mohamed Taha \\ University of Nebraska Medical Center \\ Arun Swaminathan \\ University of Nebraska Medical Center
}

Tell us how you used this information in this short survey.

Follow this and additional works at: https://digitalcommons.unmc.edu/gmerj

Part of the Educational Assessment, Evaluation, and Research Commons, Educational Methods Commons, Higher Education Commons, Medical Education Commons, and the Neurology Commons

\section{Recommended Citation}

Crespo Artunduaga, D., Taha, M., , Swaminathan, A. An Overview of Neurology Residency Training in Epilepsy at the University Of Nebraska Medical Center. Graduate Medical Education Research Journal. 2019 Dec 13; 1(1).

https://digitalcommons.unmc.edu/gmerj/vol1/iss1/7

This Original Report is brought to you for free and open access by DigitalCommons@UNMC. It has been accepted for inclusion in Graduate Medical Education Research Journal by an authorized editor of DigitalCommons@UNMC. For more information, please contact digitalcommons@unmc.edu. 


\title{
An Overview of Neurology Residency Training in Epilepsy at the University Of Nebraska Medical Center
}

\author{
Abstract \\ Neurology residency offers a comprehensive training program over 4 years in management of various \\ neurological disorders. Epilepsy represents a common condition managed by neurologists and forms a \\ core curriculum in the training of neurology residents. We conducted an anonymous survey among the \\ trainees at our neurology program to identify knowledge and treatment gaps and help us modify our \\ training regimens to provide high impact and good quality training to our trainees. We conducted a \\ 35-question survey to determine various aspects of our neurology residents' training to identify and \\ overcome shortfalls. Our program requirements are rigorous and match up with those of other programs \\ nationwide. We present our findings below to support our assertion that our training program is an \\ excellent one and is able to provide excellent training to ensure comfort in the management of epilepsy.

\section{Keywords} \\ neurology residency, epilepsy, training

\section{Creative Commons License} \\ cc) (i) $€$ \\ This work is licensed under a Creative Commons Attribution-Noncommercial-No Derivative Works 4.0 \\ License.

\section{Cover Page Footnote} \\ I am grateful to the neurology residents for their support. Special thanks to Krishna Mourya Galla MD and \\ Erin Cameron Smith MD for their assistance!
}




\section{An Overview of Neurology Residency Training in Epilepsy at the University of Nebraska Medical Center \\ Daniel Crespo Artunduaga', Mohammed Taha', Arun Swaminathan}

${ }^{1}$ University of Nebraska Medical Center, Department of Neurology

https://doi.org/10.32873/unmc.dc.gmerj.1.1.007

\begin{abstract}
Introduction: Neurology residency offers a comprehensive training program over 4 years in management of various neurological disorders. Epilepsy represents a common condition managed by neurologists and forms a core curriculum in the training of neurology residents. We conducted an anonymous survey among the trainees at our neurology program to identify knowledge and treatment gaps, as well as to help us modify our training regimens to provide high impact and good quality training to our trainees.
\end{abstract}

Methods: We conducted a 35-question survey to determine various aspects of our neurology residents' training to identify and overcome these shortfalls.

Results: Our program meets the Accreditation Council for Graduate Medical Education (ACGME) competency requirements for a neurology residency training. We present our findings below to support our assertion that our training program matches the national standard of training and provides the necessary training in epilepsy required to practice as a general neurologist proficiently, as evidenced by the number of EEG our residents read during their residency training.

Conclusions: The UNMC Neurology residency program allows residents to achieve their milestones in the field of epilepsy management and we continue to search for and improve upon our shortcomings in this regard.

\section{Introduction}

Residency training represents a challenging experience for faculty members and trainees, yet it is an essential part of their careers. Neurology residency programs are designed to ensure high quality training to keep up with the burgeoning demand for neurologists and promote good quality care for an increasingly aging population. The latest figures show there are 114 training programs with 617 positions for adult neurology resident trainees across the USA. ${ }^{1}$ Epilepsy represents an important core rotation during neurology residency, with many trainees going on to enroll in advanced training fellowships in epilepsy. For the 2015 to 2016 academic year, there were about 95 accredited clinical neurophysiology fellowship programs offering 313 positions and 43 epilepsy fellowship programs with 106 available positions. ${ }^{2}$ Epilepsy prevalence in the population is at $1 \%$, making it a common complaint that is treated by neurologists and trainees. ${ }^{3}$ Studies have shown that $6-10 \%$ of patients encounters seen by residents during his/her neurology residency involved patients with epilepsy. ${ }^{4,5}$ Therefore, ensuring good training and confidence in the management of epilepsy and seizure disorders forms a basic prerequisite of neurology residency training.

Training residents to read and interpret EEG can be utilized in emergency situations and in evaluation of critically ill patients. A study has shown that adequate training on EEG using American Clinical Neurophysiology Society (ACNS) terminology allowed residents to identify seizures in critically ill patients. ${ }^{6}$ We analyzed our trainees' exposure to various aspects of epilepsy diagnosis, such as: semiology, medication-related side effects, appropriate antiepileptic medication and psychosocial implications from epilepsy diagnosis, as well as treatment of epilepsy, using an anonymous questionnaire. We sought to establish trainees' comfort and knowledge with these topics, along with potential shortfalls in their training to identify and close these learning gaps. We plan to use the data from this study to modify our training program to enable better education of our trainees and improve their overall comfort and competence in the diagnosis and treatment of epilepsy and seizure disorders.

\section{Methods}

A survey consisting of 35 questions was emailed to the residents $(n=12)$ as part of the study. These questions were a mix of multiple choice questions and open-ended answers (requiring descriptive, textual answers). Residents were instructed to anonymously complete this survey and return it to the chief resident, who then forwarded the results to the study personnel, thus ensuring deidentification of all survey responses. Twelve residents ranging from PGY 2 to PGY 4 were included in this study. PGY-1 residents were excluded from the study since at the time of survey administration, they had only two months of general neurology, as they rotate through medicine rotations during this first year. We included training experiences from the University of Nebraska Medical Center Hospital (UNMC) and the Omaha Veterans Administration (VA) Hospital.
Survey questions included the responder's level of training, followed by the average number of epilepsy patients that they saw on an inpatient and outpatient basis. Questions also included the number of EEGs that trainees had read (including routine EEG, which is a 20 to 60 minute study, and video EEGs) and reported on, along with their comfort levels in interpreting different findings on an EEG. This was then followed by questions testing their exposure to various aspects of epilepsy diagnosis and treatment.

We also inquired about their exposure to the Epilepsy Monitoring Unit (EMU). The EMU is a specialized inpatient unit designed to evaluate, diagnose, and treat seizures in patients. EMU's are able to offer specialized diagnosis and treatment to patients with epilepsy. We then asked trainees about their: exposure to research material, experiences with advanced treatment practices in epilepsy, future plans, and any other opinions that they had regarding epilepsy training that was not covered in this survey.

Study personnel then analyzed the results using descriptive statistics from these anonymized responses and compiled them. We analyzed various trends, compared them to nationwide standards from the ACGME database, and sought to establish a gradient of responses based upon the training level of the responder.

\section{Results}

The neurology residents reported that they would see about 3-5 adult epilepsy patients per week at UNMC and about 1-3 epilepsy patients per week at the VA on average (Table 1). This included both inpatient and outpatient experiences at both centers. They estimated that $25-30 \%$ of the inpatients at UNMC presented with epilepsy or seizure related complaints while it was $10-20 \%$ at the VA. Residents also reported that they would see 2-5 patients per week for evaluation of episodes of loss of awareness from undetermined causes and some of these resulted in epilepsy diagnosis. Their comfort levels in assessing such spells increased with the progression of their training. None of the PGY-2 residents felt comfortable while 30\% of the PGY-3 residents expressed some degree of comfort and $75 \%$ of the PGY-4 residents felt quite comfortable in assessing these spells. Residents estimated that they saw 3-5 
pediatric epilepsy patients per week during their 3-month child neurology rotation but did not see pediatric patients at other times of their training. Residents estimated that they spent about 20-30 minutes with each follow up patient, while new patients took up to 3045 minutes each. Notably, $30 \%$ of the trainees found this time insufficient (Table 1).

Residents estimated that they read about 5-10 EEGs during their PGY-2. EEG studies are of two types; routine EEGs that last from 20 to 60 minutes and video EEG studies that last for more than 24 hours. This number, on average, increased to about 30-40 EEGs by the time they were finishing PGY 4. Most of these EEGs were routine studies and residents had very limited reading experience with video EEG studies. All residents claimed to be comfortable with identifying basic features of EEGs containing normal findings in sleep and wakefulness and common waveforms, but $60 \%$ of the residents claimed that they were less comfortable with identifying complicated seizures, certain benign variants, and uncommon EEG findings or strange artifacts. In total, $90 \%$ of residents were comfortable with identifying common seizures on EEG by the end of their training.

Residents reported that they, on average, called in the EEG tech about 5-10 times a month for an urgent video EEG hookup while on call. They noted that they usually needed to discuss urgent issues regarding epilepsy patents with the on call attending 8-15 times a month as well. On average, residents noted that they usually spent about a week every year on the epilepsy-monitoring unit (EMU) and that they usually had less than 4 weeks experience on the EMU over the entire duration of their residency training. Notably, $75 \%$ of the residents had less than three weeks of EMU experience, while the remaining 25\% had three to four weeks of experience. Most trainees did not have the opportunity to work with an epilepsy surgery patient on the EMU.

Eighty percent of the residents reported that the most common challenges they experienced while dealing with epilepsy patients involved choosing antiepileptic drugs (AEDs) appropriately, identifying non-epileptic seizures and non-convulsive status, and managing side effects of AEDs. Other challenges identified were working jointly with non-neurology providers, such as medical/surgical ICU teams, in managing patients with non-convulsive status epilepticus or patients post-cardiac arrest. Most residents reported having minimal to or no exposure working with epilepsy devices like a vagal nerve stimulator (VNS). In total, $80 \%$ of the residents had seen less than five patients with a VNS during their residency.

All residents were satisfied with their current weekly didactic schedule with a single epilepsy related lecture a week, but did have some topics to which they wanted more exposure. Desired topics of interest included psychogenic spells, epilepsy surgery, EEG interpretation, AED management, and epilepsy in pregnant or breastfeeding patients. Many residents reported that the commonest topics that they counseled patients about included driving restrictions, cannabidiol use, psychosocial aspects of their condition, and AED maintenance.

Half of the residents had not attended a single epilepsy surgical conference during their training (Table 2). The junior residents (PGY-2) had not interacted with the epilepsy neurosurgeons, although the senior residents (PGY-3 and PGY-4) residents had worked alongside them at least once.

Thirty-five percent of residents had participated in epilepsy related research during their residency while about $15 \%$ of them have attended a national conference in epilepsy during their training. Thirty-five

\section{Table 1.}

Descriptive data points taken from neurology residents.

\begin{tabular}{|c|c|}
\hline The average number of epilepsy patients seen by a resident per year (UNMC) & $150-250$ \\
\hline The average number of epilepsy patients seen by a resident per year (VA) & $50-150$ \\
\hline $\begin{array}{l}\text { The average number of paediatrics epilepsy patients seen by a resident during } \\
3 \text { months period }\end{array}$ & $36-60$ \\
\hline $\begin{array}{l}\text { The average total number of EEG reads done by a resident (until time of this } \\
\text { evaluation) }\end{array}$ & $\begin{array}{l}\text { PGY2 : 5-10 } \\
\text { PGY3: } 15-25 \\
\text { PGY4:30-40 }\end{array}$ \\
\hline The average number of times to call technician in for EEG hook-up per month & $5-10$ \\
\hline $\begin{array}{l}\text { The average number of times to call epilepsy attending regarding patient to talk } \\
\text { at night per month }\end{array}$ & $8-15$ \\
\hline $\begin{array}{l}\text { The average number of times that a resident needs input from epilepsy } \\
\text { attending for ward patients per month }\end{array}$ & 4-5 \\
\hline The average time spent with each epilepsy patient in minutes & $\begin{array}{l}\text { New patient : } 30-45 \\
\text { Follow up patient: } 20-30\end{array}$ \\
\hline $\begin{array}{l}\text { The percentage of residents who find the time spent with epilepsy patients to be } \\
\text { insufficient }\end{array}$ & $30 \%$ \\
\hline
\end{tabular}

\section{Table 2.}

Survey results regarding scholarly activity during neurology residency.

$40-50 \%$ of residents have not attended a single surgical/epilepsy conference

\begin{tabular}{l}
\hline $80 \%$ of residents have not attended a national level epilepsy conference during residency (AES / ACNS ). \\
\hline $60 \%$ of residents would be interested / potentially interested in conducting an epilepsy research project during \\
residency. \\
\hline $70 \%$ of residents have presented at least one complicated epilepsy patient during their residency on rounds/ \\
conferences \\
\hline $30 \%$ of residents have published epilepsy-related papers/posters in local hospital conferences. \\
\hline
\end{tabular}

percent of them had published at least one epilepsy related research paper or poster presentation during their training at a regional or national level conference (Table 2).

About $40 \%$ of the neurology residents reported having a family member or close acquaintance with epilepsy.

\section{Discussion}

The volume of patients seen by our trainees during their residency is adequate enough to ensure a good depth of training and enable comfort in the management of epilepsy, given that it allows residents to achieve their appropriate milestones during and at completion of residency. While they have sufficient exposure, in terms of time spent, to pediatric epilepsy as well, ensuring time on the pediatric service one month a year, rather than a single 3 months block may ensure that they are able to keep up with the latest treatment guidelines and recommendations on the aforementioned subject. They may also benefit from having a continuity clinic for their pediatric patients, whenever possible. While most residents find time spent with patients adequate either at the outpatient clinic or inpatient wards, about a third of them find of residents have published epilepsy-related papers/posters in local hospital conferences. 
it insufficient. This was mostly due to time spent in documentation in electronic health records and coordination of care. We plan to train our residents to adopt a more streamlined approach to spend time with these patients efficiently and enable them to manage them well during their appointments.

Our residents have adequate volumes of EEG for reading during their training. Most programs have a requirement that trainees complete reading at least 25 EEGs during their residency, and our program surpasses this requirement. In order to be considered competent on EEG interpretation, our program requires reading 50 routine and 15 video EEG at graduation. By the end of their training, $100 \%$ of our trainees are able to identify common features of EEGs along with common seizures and abnormalities, which helps them achieve the level 4 competency guideline needed for graduation (Table 3). Our trainees, thus, have sufficient and high quality exposure to EEG reading during their residency.
Call requirements for epilepsy management were analyzed for our residents and were noted to be adequate. They call in the EEG technician in a timely manner and are usually able to identify the need for emergent EEG monitoring correctly on most occasions. They also did well, as far as the management of emergencies in epilepsy was concerned, as judged by their supervising faculty.

The common challenges that residents reported while working with patients with seizures were selection of appropriate AEDs, identification of non-convulsive status epilepticus and non-epileptic spells. Other challenges encountered during residency were understanding concepts of epilepsy surgery, as well as seizure management of pregnant and breastfeeding patients.

Overall, our residents showed appropriate progress as measured by evaluation of their milestones and increasing levels of confidence as they transitioned through residency. Our trainees were able to meet the required level 4 competency requirement needed for graduation, especially with managing common conditions, improving knowledge of epilepsy surgery, and identifying the need for the same and referring patients appropriately (Tables 3 and 4). Our didactic schedule has covered all the topics needed for them to complete their training requirements and has been modified to address the before mentioned topics such as management of non-epileptic spells, concepts of epilepsy surgery, seizure management in pregnant and breastfeeding patients and improve their understanding of the finer points of epilepsy like device management and programming as well as video EEG training. Most residents expressed a need to learn advanced topics that would help them further their knowledge and interest of epilepsy.

EMU exposure remains an important point of discussion for our trainees. Our residents spent less than 3 weeks, on average, over their 4-year residency working with specialized EMU patients. Most programs usually offer at least 6-12 weeks on the EMU over the duration of their residency training. Our

Table 3.

ACGME competency requirements for EEG reading during neurology residency training - Level 4 is the graduation target.

\begin{tabular}{|c|c|c|c|c|}
\hline \multicolumn{5}{|c|}{ Electroencephalogram (EEG) - Patient Care } \\
\hline Level 1 & Level 2 & Level 3 & Level 4 & Level 5 \\
\hline $\begin{array}{l}\text { - Explains an EEG procedure in } \\
\text { non-technical terms }\end{array}$ & $\begin{array}{l}\text { - Uses appropriate terminology } \\
\text { related to EEG (e.g. montage, } \\
\text { amplitude, frequency) }\end{array}$ & $\begin{array}{l}\text { - Describes normal EEG } \\
\text { features of wake and sleep } \\
\text { states } \\
\text { - Recognizes EEG patterns of } \\
\text { status epilepticus } \\
\text { - Recognizes common EEG } \\
\text { artifacts }\end{array}$ & $\begin{array}{l}\text { - Interprets common EEG } \\
\text { abnormalities and creates a } \\
\text { report } \\
\text { - Recognizes normal EEG } \\
\text { variants }\end{array}$ & $\begin{array}{l}\text { - Interprets uncommon EEG } \\
\text { abnormalities } \\
\text { - Describes normal and some } \\
\text { abnormal EEG features of } \\
\text { wake and sleep states in } \\
\text { children }\end{array}$ \\
\hline
\end{tabular}

Comments:

\section{Table 4.}

ACGME competency requirements for the management of epilepsy during neurology residency training - Level 4 is the graduation target.

\begin{tabular}{|c|c|c|c|c|}
\hline Epilepsy - Patient Care & & & & \\
\hline Level 1 & Level 2 & Level 3 & Level 4 & Level 5 \\
\hline $\begin{array}{l}\text { - Recognizes when a patient } \\
\text { may have a seizure }\end{array}$ & $\begin{array}{l}\text { - Identifies epilepsy } \\
\text { phenomenology, and } \\
\text { classification of seizures and } \\
\text { epilepsies } \\
\text { - Diagnoses convulsive status } \\
\text { epilepticus }\end{array}$ & $\begin{array}{l}\text { - Diagnoses and manages } \\
\text { common seizure disorders } \\
\text { and provides antiepileptic drug } \\
\text { treatment } \\
\text { - Diagnoses non-convulsive } \\
\text { status epilepticus } \\
\text { - Manages convulsive and non- } \\
\text { convulsive status epilepticus }\end{array}$ & $\begin{array}{l}\text { - Diagnoses uncommon seizure } \\
\text { disorders } \\
\text { - Appropriately refers } \\
\text { an epilepsy patient for } \\
\text { surgical evaluation or other } \\
\text { interventional therapies }\end{array}$ & $\begin{array}{l}\text { - Manages uncommon seizure } \\
\text { disorders } \\
\text { - Engages in scholarly activity } \\
\text { in epilepsy (e.g., teaching, } \\
\text { research) }\end{array}$ \\
\hline
\end{tabular}


current training schedule has made it difficult to allocate more time for specialized resident coverage of the EMU as we have previously had only 4 residents per year. We expect to increase the amount of time our residents will spend on the EMU as we will increase our yearly complement of residents from 4 to 5 this year, freeing up more time for the residents to work on the EMU. This is expected to improve their exposure to the field of epilepsy and increase their comfort level in handling complicated epilepsy patients.

Epilepsy surgical conferences represent an excellent opportunity for our trainees to understand the management of complicated epilepsy. Eighty percent of our trainees did not attend even a single surgical conference during their entire residency and we have instituted a policy that residents should attend at least 3 conferences during their training, which averages to one a year and is highly manageable. This would offer them insightful exposure to surgical management of epilepsy and help them develop their instincts to identify and refer patients correctly for epilepsy surgery, in a timely manner. Additionally, this would fulfill another core requirement to meet level 4 competency guidelines.

Research participation is highly encouraged in our program and our results noted adequate participation rates with a total of $100 \%$ for our residents. We aim to improve their national conference attendance rates to enable greater exposure to epilepsy and to encourage them to improve their professional and social connections.

Personal exposures and connections do play a role in pursuing a residency in neurology. It was not at all surprising that $40 \%$ of our trainees reported knowing someone close to them with epilepsy. Epilepsy remains a common inspiration for medical students to pursue a neurology residency with the goal of helping to improve treatment for it and address the burden and stigma imposed by this condition on society. Our trainees

\section{References}

1 National Resident Matching Program, Results and Data: 2019 Main Residency Match ${ }^{\circledR}$. National Resident Matching Program, Washington, DC. 2019. https://mk0nrmp3oyqui6wqfm.kinstacdn.com/ wp-content/uploads/2019/04/NRMP-Results-andData-2019_04112019_final.pdf. Accessed June 30, 2019.

2 Vidaurre J, Campbell J. The case for an epilepsy and clinical neurophysiology match. Pediatric neurology. 2017 Jul 1;72:5-6.

3 Zack MM, Kobau R. National and state estimates of the numbers of adults and children with active epilepsy — United States, 2015. MMWR. 2017;66:821-825. DOI: $10.15585 / \mathrm{mmwr} . \mathrm{mm} 6631 \mathrm{a} 1$

4 Ances B. The more things change the more they stay the same: a case report of neurology residency experiences. Journal of neurology. $2012 \mathrm{Jul}$ 1;259(7):1321-5.

5 D'Esposito M. Profile of a neurology residency. Archives of neurology. 1995 Nov 1;52(11):1123-6.

6 Ding JZ, Mallick R, Carpentier J, McBain K, Gaspard $\mathrm{N}$, Westover MB, Fantaneanu TA. Resident training and interrater agreements using the ACNS critical care EEG terminology. Seizure. 2019 Mar 1;66:76-80.

7 The Neurology Milestone Project. Retrieved July 25, 2019, from https://www.acgme.org/ Portals/0/PDFs/Milestones/NeurologyMilestones. pdf?ver=2015-11-06-120526-253. reaffirmed this personal connection in making training choices and this was corroborated by the survey results.

\section{Conclusions}

Epilepsy remains a highly prevalent condition and its management forms an essential aspect of neurology residency training. UNMC Neurology residency program offers wellrounded and more than adequate training that allows residents to achieve their milestones in the field of epilepsy management and we continue to search for and improve on our shortcomings in this regard. Complementary efforts by residents and faculty members along with support from colleagues in other departments remain a cornerstone in maintaining excellence in this field. Our didactic and research efforts continue to improve and are showcased nationally by increasing output of presentations and posters as well. We aim to continue working towards improvement on a daily basis. 